\title{
Personal Correlates of Covid-19 Vaccine Hesitancy
}

\author{
Adrian Furnham \\ Department of Leadership and Organisational Behaviour, Norwegian Business School (BI), Nydalveien, Olso, Norway \\ Email: adrian@adrianfurnham.com
}

How to cite this paper: Furnham, A. (2022) Personal Correlates of Covid-19 Vaccine Hesitancy. Health, 14, 38-45.

https://doi.org/10.4236/health.2022.141003

Received: December 11, 2021

Accepted: January 10, 2022

Published: January 13, 2022

Copyright (c) 2022 by author(s) and Scientific Research Publishing Inc. This work is licensed under the Creative Commons Attribution International License (CC BY 4.0).

http://creativecommons.org/licenses/by/4.0/

\begin{abstract}
The aim of the study was to examine some overlooked individual difference (demography, ideology, ability) correlates of attitudes to being vaccinated with the Covid-19 vaccine. Six hundred and sixteen adults were asked about receiving the COVID-19 vaccine. The relationship between demographic (age, sex, education), ideology (political and religious beliefs), intelligence (cognitive ability) and attitudes to vaccination (acceptance, hesitancy, rejection) was examined. Correlations and regressions indicated that vaccine hesitancy and rejection were associated primarily with intelligence and political beliefs as well as mental illness history, as well as religious beliefs. Effect sizes were however small. Limitations are acknowledged.
\end{abstract}

\section{Keywords}

Covid Vaccine, Demographics, Ideology, Intelligence

\section{Introduction}

There is general agreement that vaccines are the best weapon against the COVID19 virus, yet it is clear that not everybody is willing to accept the vaccine even when freely offered and strongly recommended by medical experts [1] [2]. This study was designed to examine the characteristics of such individuals unwilling to accept, or hesitant about, accepting a vaccine. This has attracted a good deal of recent research [3] and is of considerable concern to health administrators and politicians.

We asked British people in early March 2021 "Have you had the COVID-19 vaccine, or do you intend to have the COVID-19 vaccine if it is offered to you?". They were offered three responses: Yes, Maybe and No.

Many studies have examined the acceptance vs rejection of various types of 
vaccination [4] [5]. Some have focused on individual differences [6] [7]. Others have shown that refusal/hesitancy is associated with conspiracy beliefs [8] [9]. Some published studies were conducted before any Covid-19 vaccines were available and tried to anticipate the reasons why some people would accept vs reject it [10]. They have been done in many countries [11] [12]. Both small scale and larger studies with representative samples have highlighted demographic, and ideology (beliefs) correlated of vaccination attitudes and behaviour [13].

Murphy et al. [2] found, in study of British and Irish respondents that there were similar rates of vaccine hesitance (26\% and $25 \%)$ and resistance (9\% and $6 \%)$. The profile of vaccine hesitant/resistant persons was that they were more self-interested, distrusting of experts and authority figures (i.e., scientists, health care professionals, the state), more likely to hold strong religious beliefs. They also tended to hold conspiratorial and paranoid beliefs about the intentions of others.

Lazarus et al. [14] surveyed 13,426 people in June 2020 from 19 countries and found $71.5 \%$ of participants reported that they would be "very or somewhat likely" to take a COVID-19 vaccine, while $48.1 \%$ reported that they would accept their employer's recommendation to do so. Older, better education and wealthier people were more likely to accept to vaccine and those reporting higher levels of trust in information from government sources were more likely to accept a vaccine and take their employer's advice to do so.

Haakonsen and Furnham [15] tested around four hundred adults and found conservative political orientation, religiosity, Cluster A Personality Disorders, and conspiracy thinking correlated negatively to vaccine acceptance. Binary logistic regression analysis showed that personal ideology, general conspiracy theory adherence, and personality disorders were the strongest indicators of vaccine acceptance and rejection.

This study extended the above study on a bigger population, and examining some overlooked variables compared to other studies. In addition to demographic and ideological factors we assessed participants' self-reported mental health history and intelligence (cognitive ability test score). In line with previous studies on attitudes to vaccinations (see above) it was hypothesised that all nine individual difference variables examined would relate to vaccination hesitancy: thus it was predicted $\mathrm{H} 1$ females more than males; $\mathrm{H} 2$ younger rather than older; $\mathrm{H} 3$ less well educated more than educated; $\mathrm{H} 4$ the more rather than less religious; $\mathrm{H} 5$ the more conservative rather than the politically liberal; $\mathrm{H} 6$ the less rather than more optimistic; $\mathrm{H} 7$ the more rather than less believers in the after-life; H8 those with more rather than less a history of mental disorder; and $\mathrm{H} 9$ the less rather than more intelligence, would be more vaccine hesitant.

\section{Method}

\subsection{Participants}

In all, 616 people took part: 307 male, 309 female. They ranged in age from 26 to 
71 , with a mean of 39.9 years ( $S D=11.63$ years). In all, $54 \%$ were graduates, $93 \%$ were British nationals and $60.3 \%$ owned their own homes. They were all working and indicated their occupation which was very varied, including accountants, health workers and people in IT.

\subsection{Measures}

1) COVID-19 Question. Participants were asked, "Have you had the COVID19 vaccine, or do you intend to have the COVID-19 vaccine if it is offered to you?". Responses were classified as vaccine accepting if they responded "Yes", hesitant if they responded "Maybe", and resistant if they responded "No" [15].

2) Personal details. They also rated their beliefs on various 10-point scales: Religious $($ Not at all $=1$ to Very $=10)($ Mean $=2.29, S D=2.90)$, Politics (Conservative $=0$ to Liberal $=10)$. On an 8 point scale the assessed their level of optimism $($ Mean $=4.70, S D=2.17)$. Asked about whether they believed in Life after Death $36.7 \%$ said yes, and $63.3 \%$ no. Asked if they had ever had (been diagnosed with) a mental disorder $14.2 \%$ said yes, $82.2 \%$ no and $3.6 \%$ said they preferred not to say.

3) The Wonderlic Personnel Test [16]. This 50-item test can be administered in 12 minutes and measures general intelligence. Items include word and number comparisons, disarranged sentences, story problems that require mathematical and logical solutions. The test has impressive norms and correlates very highly $(r=0.92)$ with the WAIS-R. In this study we used 16 items from Form A $(14,15,18,21,24,27,28,29,30,32,33,34,36,37,43,46)$ which did not require presenting geometric figures The measure has been used in many studies. In this study there were no time limits/restrictions which may have inflated the scores.

\subsection{Procedure}

Departmental ethical approval was gained prior to data collection (CEHP/514/ 2017) Data was collected on-line through Prolific, a platform like the betterknown Amazon-Turk, Participants were compensated for their time (receiving $£ 1.00$ ). We specified we wanted people over 21 years. Usual data cleansing and checking was done, such as missing data, time taken etc. The study was run in March 2021 when the vaccination programme was progressing rapidly. Power analysis indicated that this size $\mathrm{N}$ was more than adequate.

\section{Results}

Correlations showed 7/9 hypothesised correlations were significant (See Table 1). Table 2 shows the ANOVAs between the three groups for each of the personal factors followed by Scheffe post-hoc tests. Six were significant, four at the $p<0.001$ level though effect sizes shown were not large. The biggest differences were on politics and intelligence which showed those who were willing to have the vaccination were politically more liberal and intelligence than the other two 
Table 1. Correlations between the variables.

\begin{tabular}{|c|c|c|c|c|c|c|c|c|c|c|}
\hline & Mean & SD & 1 & 2 & 3 & 4 & 5 & 6 & 7 & 8 \\
\hline (1) COVID & 1.46 & 0.72 & & & & & & & & \\
\hline (2) Sex & 1.50 & 0.50 & $-0.09^{\star}$ & & & & & & & \\
\hline (3) BirthYear & 1986.31 & 9.54 & 0.00 & $-0.15^{\star * *}$ & & & & & & \\
\hline (4) Schooling & 15.50 & 3.72 & $-0.17^{\star * *}$ & 0.06 & 0.07 & & & & & \\
\hline (5) Religious & 2.97 & 2.42 & $0.13^{\star *}$ & -0.04 & $-0.09^{*}$ & -0.03 & & & & \\
\hline (6) Politics & 6.06 & 1.70 & $-0.24^{\star * \star}$ & $0.21^{\star * *}$ & 0.08 & $0.17^{\star * *}$ & $-0.30^{\star \star}$ & & & \\
\hline (7) Optimist & 4.71 & 2.18 & -0.04 & 0.00 & 0.06 & 0.07 & -0.04 & $0.11^{\star *}$ & & \\
\hline (8) MentDisord & 1.94 & 0.51 & $0.14^{\star * *}$ & $-0.10^{*}$ & 0.07 & 0.05 & 0.05 & $-0.14^{\star *}$ & $-0.10^{*}$ & \\
\hline (9) IQTotal & 10.78 & 2.96 & $-0.24^{\star * *}$ & -0.06 & -0.00 & $0.16^{* * *}$ & $-0.27^{\star \star}$ & $0.21^{\star * *}$ & -0.03 & 0.04 \\
\hline
\end{tabular}

${ }^{* *} \mathrm{p}<0.001 ;{ }^{* *} \mathrm{p}<0.01 ;{ }^{*} \mathrm{p}<0.05$.

Table 2. Attitudes to Covid vaccination.

\begin{tabular}{|c|c|c|c|c|c|c|c|c|}
\hline & \multicolumn{2}{|c|}{ Yes $(67 \%)$} & \multicolumn{2}{|c|}{ Maybe (19\%) } & \multicolumn{2}{|c|}{ No $(14 \%)$} & \multirow[t]{2}{*}{$F$} & \multirow[t]{2}{*}{$E S$} \\
\hline & Mean & SD & Mean & SD & Mean & SD & & \\
\hline Sex & 1.53 & 0.50 & 1.46 & 0.50 & 1.41 & 0.50 & 2.33 & 2.33 \\
\hline Birth Year & 1986.26 & 9.95 & 1986.59 & 8.38 & 1986.13 & 9.49 & 0.07 & 0.07 \\
\hline Schooling & $15.91^{\mathrm{a}}$ & 3.56 & $15.14^{\mathrm{ab}}$ & 3.80 & $14.11^{\mathrm{b}}$ & 4.12 & $8.81^{\star * *}$ & 0.029 \\
\hline Religious & $2.77^{\mathrm{a}}$ & 2.31 & $3.16^{\mathrm{ab}}$ & 2.56 & $3.60^{\mathrm{b}}$ & 2.63 & $4.33^{\star}$ & 0.018 \\
\hline Politics & $6.33^{\mathrm{a}}$ & 1.66 & $5.68^{\mathrm{b}}$ & 1.51 & 5.25 & 1.87 & $17.98^{\star * *}$ & 0.057 \\
\hline Optimist & 4.73 & 2.18 & 4.80 & 2.08 & 4.41 & 2.37 & 2.37 & 0.89 \\
\hline Afterlife & $1.69^{\mathrm{a}}$ & 0.46 & $1.54^{\mathrm{b}}$ & 0.50 & $1.51^{\mathrm{b}}$ & 0.50 & $7.89^{\star * *}$ & 0.027 \\
\hline Mental Disorders & $1.89^{\mathrm{a}}$ & 0.46 & $2.04^{\mathrm{b}}$ & 0.58 & $2.06^{\mathrm{b}}$ & 0.55 & $6.20^{* *}$ & 0.020 \\
\hline IQ Total & $11.24^{\mathrm{a}}$ & 2.79 & $10.32^{\mathrm{b}}$ & 3.02 & $9.29^{c}$ & 3.04 & $17.90^{* * *}$ & 0.056 \\
\hline
\end{tabular}

Coded: Sex: 1 = male, 2 = Female; Afterlife 1 = yes, 2 = no; Mental Disorders 1 = Yes, 2 = no; ${ }^{\text {a,b,c }}$ represent results of the Scheffe Post Hoc test where different letters indicate significant differences at $\mathrm{p}<0.01$. ES is effect size as determined by the partial eta square.

groups. The post hoc tests showed that, with the exception of schooling and religion, the vaccine acceptance group was different from the other two groups. Indeed the "Maybe" and "No" group were not different except on IQ where all three groups differed significantly.

This was followed by a multiple regression shown in Table 3. This indicated that better educated, brighter people with less conservative political beliefs and less history of mental disorders were more willing to be vaccinated. Then the "Maybe" and "No" group were combined and performed a Binary regression but the results were no different. The regression explained just a tenth of the variance. 
Table 3. Regression of vaccination choice onto nine factors.

\begin{tabular}{ccccc}
\hline & $B$ & $S E$ & Beta & $t$ \\
\hline Sex & -0.05 & 0.06 & -0.03 & -0.78 \\
Birth Year & 0.00 & 0.00 & 0.01 & 0.23 \\
Schooling & -0.02 & 0.01 & -0.10 & $-2.29^{\star}$ \\
Religious & -0.00 & 0.02 & -0.01 & -0.22 \\
Politics & -0.06 & 0.02 & -0.14 & $-3.01^{\star *}$ \\
Optimist & 0.00 & 0.01 & 0.00 & 0.00 \\
Afterlife & -0.07 & 0.08 & -0.04 & -0.83 \\
Mental Disorders & 0.20 & 0.07 & 0.13 & $3.03^{\star *}$ \\
IQ Total & -0.04 & 0.01 & -0.17 & $-3.77^{\star * *}$ \\
Adjusted $R^{2}$ & & & 0.10 & \\
$F$ & & & & \\
$p$ & & & 0.000 & \\
\hline
\end{tabular}

${ }^{* *} \mathrm{p}<0.001 ;{ }^{* *} \mathrm{p}<0.01{ }^{*} \mathrm{p}<0.05$

\section{Discussion}

These results confirmed those from many other studies on general, as well as specifically COVID-related, vaccination acceptance and hesitancy. It highlighted three major factors: education and ability, mental illness and politics. Many studies have shown that those who are more politically conservative are more resistant to vaccination, particularly when it is mandated by the state. They no doubt see this is an infringement of their rights and tend to be suspicious of any form of state intervention. This is also often related to trust in institutions, conservatives often favouring "small" over "big" government [17].

Interestingly in the regression the significant effects of the two religious questions ceased to be significant possibly because of the association between religion, politics and intelligence: brighter people tend to be less religious and more politically liberal/left-wing.

It was also found that those with less schooling and lower intelligence were also more resistant to vaccination. It is important to point out that this sample was skewed to being better educated and middle class: nevertheless, within that sample we found evidence of these factors playing a part. We also found that those who admitted a diagnosis (albeit unspecified) of a mental illness were more against vaccination.

In all these factors only accounted for a tenth of the variance which begs the question of what accounts for the remaining variance in the acceptance of this, or indeed, other vaccines. Exploring an individual's medical history and health beliefs may be a useful avenue to pursue.

The results of this study may come as no surprise to health workers, though nothing gives them hope for easy interventions. Intelligence and education are 
clearly related to many health outcomes including the willingness to be helped. Similarly those who have strong political views particularly if they are conservative and conspiratorial are also associated with a distrust of medical authorities [15]. The association between mental health and vaccination hesitancy is not surprising though it would be most interesting to know more about the nature of those illnesses to understand the mechanism. Inevitably it would be desirable to have more details on participants such as the answers to the following questions: Do these participants who do not want to be vaccinated have any concerns about the vaccine? What are the reasons for those who are not willing to be vaccinated? How much do these participants know about the COVID-19 virus? Are these participants worried about contracting the COVID-19 virus?

Like all others this study had limitations. Many of the constructs were measured on single item measures which are less desirable than a multi-dimensional test, using multiple items with good reliability. Also, we did not establish why people answered in the way they did to the central Covid question. They may have answered "no" for a number of reasons including both ideological and medical. Also, we did not ask whether any had indeed had Covid-19 themselves which could easily have affected the results, though we suspect very few. Equally, we did not have detailed answers to other questions like whether they had had a mental disorder which could vary from mild depression to psychotic episodes. Inevitable this was not a representative population as is typical using platforms such as prolific, which may have skewed the results on some variables like education and personal beliefs.

\section{Data Availability}

This is obtainable from the author upon request.

\section{Registration}

This paper was not pre-registered with the journal.

\section{Ethics}

This was sought and obtained (CEHP/514/2017).

\section{Informed Consent}

Participants gave consent for their anonymised data to be analysed and published.

\section{Conflicts of Interest}

There is no conflict of interest.

\section{References}

[1] Khubchandani, J., Sharma, S., Price, J.H., Wiblishauser, M.J., Sharma, M. and Webb F.J. (2021) COVID-19 Vaccination Hesitancy in the United States: A Rapid Na- 
tional Assessment. Journal of Community Health, 46, 270-277. https://doi.org/10.1007/s10900-020-00958-x

[2] Murphy, J., et al. (2021) Psychological Characteristics Associated with COVID-19 Vaccine Hesitancy and Resistance in Ireland and the United Kingdom. Nature Communications, 12, Article No. 29. https://doi.org/10.1038/s41467-020-20226-9

[3] Lin, C., Tu, P. and Beitsch, L.M. (2021) Confidence and Receptivity for COVID-19 Vaccines: A Rapid Systematic Review. Vaccines, 9, 16. https://doi.org/10.3390/vaccines 9010016

[4] Habersaat, K.B. and Jackson, C. (2020) Understanding Vaccine Acceptance and Demand and Ways to Increase Them. Bundesgesundheitsblatt-Gesundheitsforschung, 63, 32-39. https://doi.org/10.1007/s00103-019-03063-0

[5] Hornsey, M.J., Harris, E.A. and Fielding, K.S. (2018) The Psychological Roots of Anti-Vaccination Attitudes: A 24-Nation Investigation. Health Psychology, 37, $307-$ 315. https://doi.org/10.1037/hea0000586

[6] Johnson, M.O. (2000) Personality Correlates of HIV Vaccine Trial Participation. Personality and Individual Differences, 29, 459-467.

https://doi.org/10.1016/S0191-8869(99)00206-8

[7] Patty, N.J., et al. (2017) To Vaccinate or Not to Vaccinate? Perspectives on HPV Vaccination among Girls, Boys, and Parents in the Netherlands: A Qmethodological Study. BMC Public Health, 17, Article No. 872.

https://doi.org/10.1186/s12889-017-4879-2

[8] Alper, S., Bayrak, F. and Yilmaz, O. (2020) Psychological Correlates of COVID-19 Conspiracy Beliefs and Preventive Measures: Evidence from Turkey. Current Psychology, 41, 1-10. https://doi.org/10.31234/osf.io/mt3p4

[9] Pummerer, L., Böhm, R., Lilleholt, L., Winter, K., Zettler, I. and Sassenberg, K. (2020) Conspiracy Theories and Their Societal Effects during the COVID-19 Pandemic. Social Psychological and Personality Science, 13, 49-59. https://doi.org/10.31234/osf.io/y5grn

[10] Neumann-Böhme, S., et al. (2020) Once We Have It, Will We Use It? A European Survey on Willingness to Be Vaccinated against COVID-19. European Journal of Health Economy, 21, 997-982. https://doi.org/10.1007/s10198-020-01208-6

[11] Edwards, B., Biddle, N., Gray, M. and Sollis, K. (2021) COVID-19 Vaccine Hesitancy and Resistance: Correlates in a Nationally Representative Longitudinal Survey of the Australian Population. PLoS ONE, 16, e0248892. https://doi.org/10.1371/journal.pone.0248892

[12] Schwarzinger, M., Watson, V., Arwidson, P., Alla, F. and Luchini, S. (2021) COVID19 Vaccine Hesitancy in a Representative Working-Age Population in France: A Survey Experiment Based on Vaccine Characteristics. The Lancet Public Health, 6, e210-e221. https://doi.org/10.1016/S2468-2667(21)00012-8

[13] Lalot, F., Heering, M.S., Rullo, M., Travaglino, G.A. and Abrams, D. (2020) The Dangers of Distrustful Complacency: Low Concern and Low Political Trust Combine to Undermine Compliance with Governmental Restrictions in the Emerging Covid-19 Pandemic. Group Processes \& Intergroup Relations, 25.

[14] Lazarus, J.V., Ratzan, S.C., Palayew, A., Gostin, L.O., Larson, H.J., Rabin, K., Kimball, S. and El-Mohandes, A. (2021) A Global Survey of Potential Acceptance of a COVID-19 Vaccine. Nature Medicine, 27, 225-228. https://doi.org/10.1038/s41591-020-1124-9

[15] Haakonsen, J. and Furnham, A. (2022) COVID-19 Vaccination, Conspiracy Theories, and Ideology. Journal of Health Psychology. IN Press. 
[16] Wonderlic, E. (1990) Wonderlic Personnel Test. WP, Libertyville.

[17] Eysenck, H. and Wilson, G. (1978) The Psychological Basis of Ideology. MTP Press, Lancaster. 